\title{
Pathological findings after percutaneous transluminal coronary angioplasty
}

\author{
KYOICHI MIZUNO, AKIRA KURITA, NOBORU IMAZEKI \\ From the Department of Emergency, the First Department of Internal Medicine, and the Department of Pathology, \\ National Defense Medical College, Saitama, Japan
}

SUMMARY Ten serial pathological cross sections at $1 \mathrm{~mm}$ intervals of both the left anterior descending artery at the site of a percutaneous transluminal coronary angioplasty and of the circumflex artery in the untreated stenotic area were studied at necropsy in a patient who died immediately after the procedure. The extent of calcification and atheroma were similar in both branches. Intimal or medial splitting, desquamation, and plaque fracture were present in the left anterior descending artery. No typical pathological findings were seen in the circumflex artery.

This study suggests that the original stenotic lumen may have been enlarged as a result of plaque splitting.

Percutaneous transluminal coronary angioplasty is an innovative treatment for selected patients with coronary artery disease. Despite the success of this technique in treating coronary artery disease little is understood of the mechanism by which the technique improves vascular patency.

Various mechanisms have been suggested including compression of the plaque, ${ }^{1-3}$ intimal plaque disruption, and splitting of the atheromatous plaque, ${ }^{4-6}$ combined with thinning or stretching of the nonatherosclerotic portion of the artery. ${ }^{78}$ Most of these previous studies did not, however, include a control-that is, a vessel not treated by transluminal angioplasty. Furthermore, many of these studies used either human necropsy specimens subjected to postmortem percutaneous transluminal angioplasty or animals in which lesions had been experimentally induced. Few were performed on human subjects who underwent antemortem angioplasty. ${ }^{9}$

We report the pathological findings in a patient who died immediately after percutaneous transluminal coronary angioplasty and compare them with those in an untreated control vessel.

Requests for reprints to Dr Kyoichi Mizuno, Department of Emergency, National Defense Medical College, 3-2 Namiki Tokorozawa, Saitama, 359 Japan.

\section{Case report}

A 61 year old man underwent coronary angiography and aortography. He had a two year history of both exertional and resting angina without previous myocardial infarction and an abdominal aortic aneurysm diagnosed by computed tomography.

Coronary arteriography was performed using Sones's technique since the Judkins's catheter would not pass into the iliac artery. Two stenotic areas of $75 \%$ and $50 \%$ narrowing were present in the left anterior descending artery and a $60 \%$ stenosis in the circumflex artery. The ejection fraction was $62 \%$ with slight hypokinesis of the anterior wall. Aortography showed tortuosity of both the abdominal aorta and the iliac artery.

The diameter of the abdominal aortic aneurysm had increased slightly since the earlier computed tomogram and surgical repair of the aneurysm was planned. Before surgery, percutaneous transluminal coronary angioplasty was performed on the left anterior descending artery using a Grüntzig dilatation catheter via the brachial artery. The technique succeeded in reducing the original stenosis in the proximal left anterior descending artery from $75 \%$ to $20 \%$ (Fig. 1). We then attempted dilatation of the mid portion of the left anterior descending artery. A few minutes after inflation of the dilatation catheter's balloon the patient complained of chest pain with concomitant ST elevation on the precordial leads. Shortly afterwards 

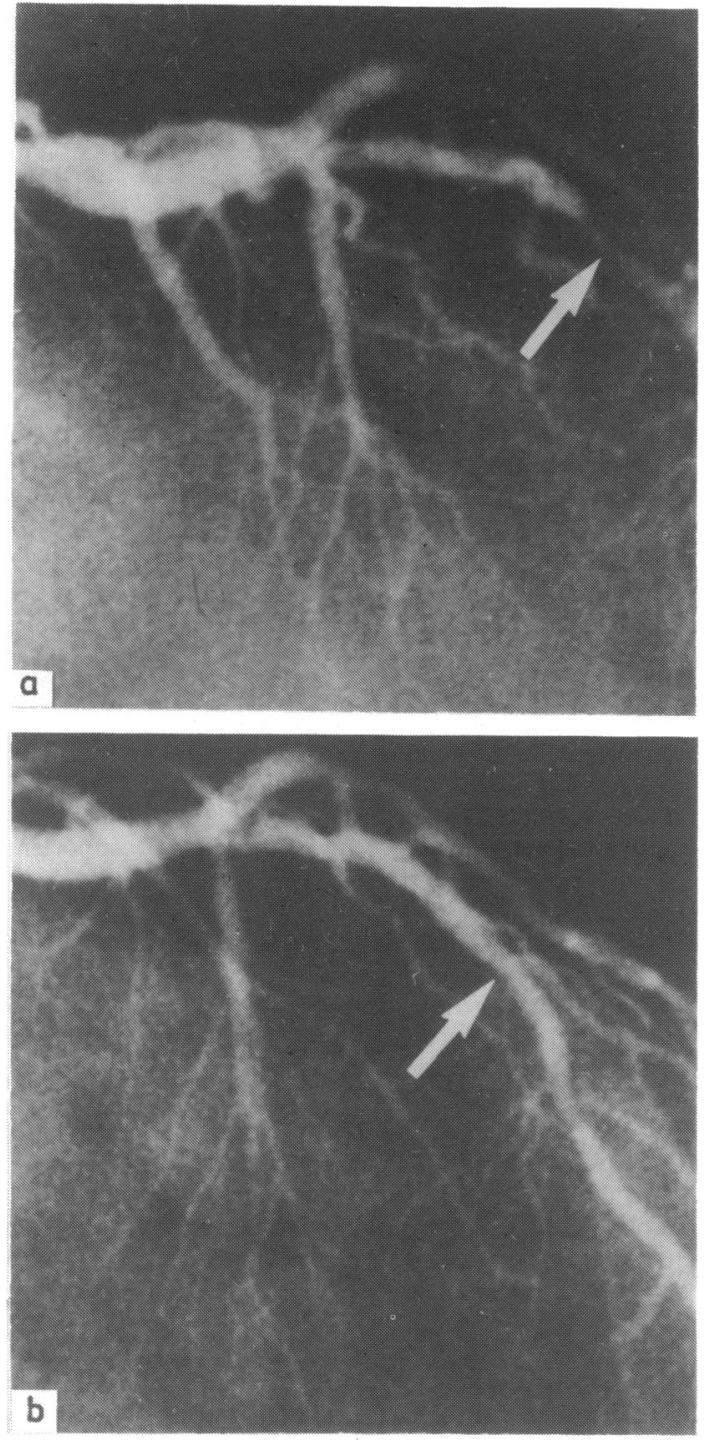

Fig. 1 (a) Coronary arteriogram (right anterior oblique projection) of $75 \%$ stenosis in left anterior descending artery before percutaneous transluminal coronary angioplasty (arrow). (b) Angiogram immediately after dilatation showing improvement in luminal diameter with $20 \%$ residual stenosis (arrow).

the patient had myocardial infarction with ventricular fibrillation. Despite numerous attempts at resuscitation including countershock and intra-aortic counterpulsation via the brachial artery he could not be revived and subsequently died.

\section{PATHOLOGY}

We obtained 10 seriai cross sections at $1 \mathrm{~mm}$ intervals
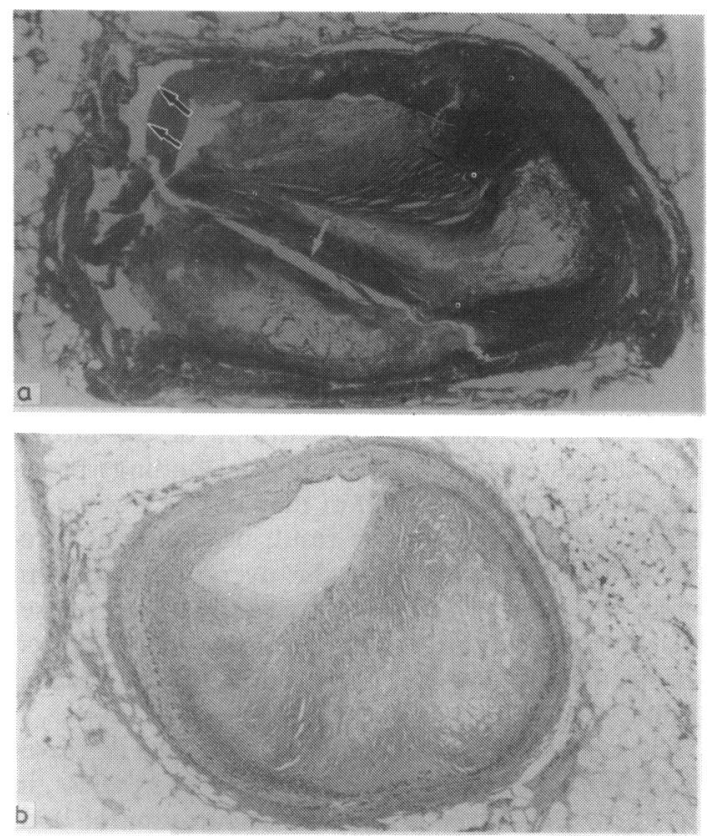

Fig. 2 Histological appearance of (a) the dilated left anterior descending artery showing intimal and medial splitting, which have led to medial dissection (black arrows), and plaque fracture (white arrow), and (b) of the untreated circumflex artery showing none of the typical pathological findings.

of the treated left anterior descending artery as well as of the stenotic area of the untreated circumflex artery. Microscopical examination showed splitting of the intima and media, plaque fracture, and desquamation of the intima in the previously stenosed but now dilated segment of the left anterior descending artery. None of these typical changes was, however, seen in any of the 10 sections of the untreated circumflex artery (Fig. 2).

The percentage narrowing of the stenosis in the circumflex artery was in fact higher in the postmortem specimen than was evident on the coronary artery angiogram. The extent of intimal calcification and atheroma were nearly identical in both the left anterior descending and circumflex arteries.

\section{Discussion}

Dotter and Judkins in their original paper on percutaneous transluminal coronary angioplasty proposed that the mechanism of dilatation was through compression of the atheromatous material, ${ }^{1}$ with which theory Grüntzig, a pioneer of percutaneous transluminal angioplasty, agreed..$^{2} 10$ 
Block et $a l^{5}$ and Castaneda-Zuniga $e t a l^{4}$ examining human necropsy specimens, animals, and angiographic evidence in two patients undergoing percutaneous transluminal coronary angioplasty, proposed that the mechanism of luminal enlargement in coronary angioplasty was not plaque compression but focal damage to the arterial wall causing splitting of either the intima or the media. Recently, in a group of patients not treated by percutaneous transluminal coronary angioplasty, Isner et al ${ }^{11}$ reported pathological findings similar to those found in patients after angioplasty - that is, splitting of the intima or media, plaque fracture, and focal disruption of the media. They suggested that the pathological findings previously described by Block et al may not be a consequence of angioplasty but the result of an artefact created during preparation of the necropsy specimen. Before drawing any conclusions we must, therefore, consider the possibility that an artefact was produced during the histological preparation of the treated coronary artery.

The extent of arterial calcific deposits also increases the likelihood of creating an artefact. Nevertheless, in our study the degree of stenotic calcification of both the left anterior descending and circumflex arteries was similar. By examining 10 sections of the treated vessel and 10 of the control vessel we increased the chances of reproducing an artefact in the control specimens. In our study, intimal or medial splitting, plaque fracture, and intimal and medial desquamation were found in the treated anterior descending artery. This is consistent with the findings of the only previous study of two patients who had undergone percutaneous transluminal coronary angioplasty antemortem. ${ }^{9}$ None of the previous pathological findings described were present in the control specimen. The fact that we did not find similar pathological findings in sections of the control specimen suggests, but does not confirm, that no artefact existed.

Our pathological study suggests that the original stenotic lumen may have been dilated by splitting of the plaque.
We thank Professor Yusuke Fuse for his advice on the pathological specimens.

\section{References}

1 Dotter CT, Judkins MP. Transluminal treatment of atherosclerotic obstruction: description of new technic and a preliminary report of its application. Circulation 1964; 30: 654-70.

2 Gruntzig AR. Transluminal dilatation of coronary-artery stenosis [Letter]. Lancet 1978; i: 263.

3 Lee G, Ikeda RM, Joye JA, Bogren HG, Demaria AN, Mason DT. Evaluation of transluminal angioplasty of chronic coronary artery stenosis. Circulation 1980; 61: 77-83.

4 Castaneda-Zuniga WR, Formanek A, Tadavarthy M, et al. The mechanism of balloon angioplasty. Radiology 1980; 135: 565-71.

5 Block PC, Baughman KL, Pasternak RC, Fallon JT. Transluminal angioplasty: correlation of morphologic and angiographic findings in an experimental model. Circulation 1980; 61: 778-85.

6 Baughman KL, Pasternak RC, Fallon JT, Block PC. Transluminal coronary angioplasty of postmortem human hearts. Am F Cardiol 1981; 48: $1044-7$.

7 Sanborn TA, Faxon DP, Waugh D, et al. Transluminal angioplasty in experimental atherosclerosis. Circulation 1982; 66: 917-22.

8 Faxon DP, Weber VJ, Haudenschild C, Gottsman SB, McGovern WA, Ryan TJ. Acute effects of transluminal angioplasty in three experimental models of atherosclerosis. Arteriosclerosis 1982; 2: 125-33.

9 Block PC, Myler RK, Stertzer S, Fallon JT. Morphology after transluminal angioplasty in human beings. $N$ Engl F Med 1981; 305: 382-5.

10 Grüntzig AR, Senning A, Siegenthaler WE. Nonoperative dilatation of coronary-artery stenosis, percutaneous transluminal coronary angioplasty. $N$ Engl $\mathcal{F}$ Med 1979; 301: 61-8.

11 Isner JM, Fortin RV. Frequency in non angioplasty patients of morphologic findings reported in coronary arteries treated with transluminal angioplasty. $\mathrm{Am} \mathcal{F} \mathrm{Car}$ diol 1983; 51: 689-93. 